\title{
Thermohygrometer dengan Penyimpanan Data Untuk Monitoring Kamar Bedah
}

\author{
Aziza Amalia ${ }^{1}$, Hanifah Rahmi Fajrin*2, Agus Susilo Wibowo ${ }^{3}$ \\ ${ }^{1,2}$ Universitas Muhammadiyah Yogyakarta, Indonesia \\ ${ }^{3}$ RSUP Dr. Sardjito Yogyakarta, Indonesia
}

INFO ARTIKEL

Alamat Web Artikel:

https://journal.umy.ac.id/index.php

/mt/article/view/9991

DOI:

https://doi.org/10.18196/mt.020115

Data Artikel:

Diterima:

12 Oktober 2020

Direview:

21 Oktober 2020

Direvisi:

02 November 2020

Disetujui:

03 November 2020

Korespondensi: hanifah.fajrin@vokasi.umy .ac.id

\begin{abstract}
ABSTRAK
Thermohygrometer merupakan alat yang berfungsi untuk mengukur suhu dan kelembaban ruangan. Dengan adanya penyimpanan data pada alat ini, dapat membantu user dalam memantau suhu dan kelembaban ruangan dan dapat mengetahui data yang disimpan sebelumnya sehingga user tidak harus mencatat data suhu dan kelembaban ruangan setiap saat. Apabila suhu dan kelembaban terpantau maka penyebaran infeksi nosokomial di ruangan operasi dapat dicegah dan tingkat kerusakan alat akibat suhu dan kelembaban dapat berkurang. Sistem elektronik terdiri atas mikrokontroler ATMega328 sebagai pusat pengendali, SHT11 sebagai sensor suhu dan kelembaban, DS1307 sebagai penanda waktu, dan SD card sebagai media penyimpanan. Pengujian dilakukan dengan membandingkan antara alat yang dibuat dengan Thermohygrometer HTC-1 LCD Digital Temperature Humidity Meter. Data suhu dan kelembaban diambil dalam 3 kondisi yaitu pada kondisi suhu panas, suhu sedang dan suhu dingin. Alat yang dirancang dapat menyimpanan data setiap 1 menit sekali, dan data yang tersimpan dalam bentuk file txt, dengan menyimpan data suhu, kelembaban, jam, hari, tanggal, bulan, tahun, dengan memori penyimpanan 8 GB. Uji kinerja modul thermohygrometer ini menunjukan hasil standar deviasi tertinggi pada data suhu yaitu $1,43^{\circ} \mathrm{C}$ dan standar deviasi tertinggi pada data kelembaban yaitu 4,697\%. Didapatkan nilai error suhu tertinggi yaitu 3\% dan error kelembaban tertinggi yaitu $2,11 \%$. Perbandingan data suhu dan kelembaban antara thermohygrometer pembanding dengan modul thermohygrometer yang dibuat menunjukan bahwa modul thermohygrometer layak guna, karena hasil dari thermohygrometer yang dirancang dengan thermohygrometer pembanding hasilnya relatif sama. Karena berdasarkan PERMENKES NO.118/2014 tentang Kompendium Alat Kesehatan, ambang batas toleransi error suhu thermohygrometer yang di perbolehkan yaitu $10 \%$.
\end{abstract}

Kata Kunci: Penyimpanan Data, Temperature, Humidity, Kamar Bedah 


\section{PENDAHULUAN}

Di dalam lingkup kesehatan terutama di rumah sakit, banyak terdapat alat elektromedik, namun alat-alat tersebut sangat rentan akan kerusakan yang diakibatkan oleh kesalahan penempatan dan penyimpanan dalam suatu ruangan. Salah satu penyebabnya yaitu akibat penyimpanan pada suhu yang sangat dingin karena AC atau suhu yang berubah-ubah. Kelembaban dikondisikan untuk meminimalkan proliferasi dan penyebaran spora jamur serta bakteri yang ditularkan melalui air di seluruh udara dalam ruangan dan juga meminimalkan kondensasi pada board komponen [1].

Suatu ruangan dikatakan layak apabila suhu dan kelembaban ruangan tersebut telah sesuai dengan ketentuan yang ada. Sesuai dengan Surat Keputusan Menteri Kesehatan RI Nomor 1204/MENKES/SK/X2004, ruang-ruang tertentu seperti ruang operasi, perlu mendapat perhatian yang khusus karena sifat pekerjaan yang terjadi di ruang-ruang tersebut, seperti proses pembedahan yang terjadi di ruang operasi. Pada ruang operasi, suhu yang telah terstandar adalah $19-24^{\circ} \mathrm{C}$, kelembaban 45-60\% dan bertekanan positif [2].

Suhu pada ruang operasi tidak boleh lebih dari $24^{\circ} \mathrm{C}$. Jika lebih dari itu, kulit pasien yang ditutup handuk steril akan cenderung berkeringat sehingga memungkinkan peningkatan jumlah kuman dalam pori-pori kulit. Kelembaban udara ruangan tidak boleh lebih dari 50\%, karena jika lebih, jamur akan mudah tumbuh [3]. Salah satu penyebab infeksi nosokomial diruang bedah karena suhu dan kelembaban tidak sesuai dengan yang semestinya[4]. Maka dari itu, suhu dan kelembaban di ruang operasi harus selalu dipantau minimal tiga kali sehari, dengan alat pengukur tingkat kelembaban dan suhu ruangan, yang disebut thermohygrometer.

Akan lebih efektif lagi apabila thermohygrometer yang ada di ruang operasi dilengkapi dengan adanya penyimpanan data. Dengan adanya penyimpanan data dapat mencegah kehilangan data suhu dan kelembaban pada hari itu. Data suhu dan kelembaban tersebut nantinya akan di arsipkan dan digunakan sebagai salah satu persyaratan penting untuk akreditasi rumah sakit setiap tiga tahun sekali. Dengan adanya thermohygrometer yang dilengkapi dengan penyimpanan data, user dapat melihat suhu dan kelembaban ruangan pada saat itu dan data-data suhu dan kelembaban akan tersimpan rapi di dalam $S D$ card tanpa harus mencatat namun akan tetap bisa terpantau. Dari latar belakang tersebut penulis bertujuan merancang suatu alat yang berjudul "Thermohygrometer dengan Penyimpanan Data untuk Monitoring Kamar Bedah".

\section{METODE PENELITIAN}

\subsection{Blok Diagram}

Cara kerja dari alat thermohygrometer ini dapat dilihat pada Gambar 3.1 berikut ini :

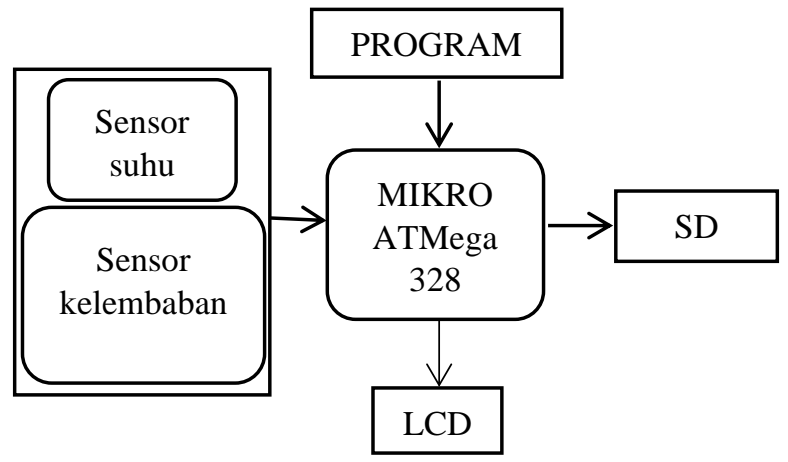

Gambar 2.1 Blok diagram Alat

Ketika power dalam posisi $O N$, maka baterai akan memberikan tegangan ke semua rangkaian. Sensor SHT 11 akan mendeteksi suhu dan kelembaban. Suhu yang terdeteksi oleh sensor, akan di proses oleh IC Microcontroller ATMega 328, selanjutnya akan dibaca dan ditampilkan pada LCD. Data yang tampil di LCD juga akan tersimpan pada $S D$ card. 


\section{Amalia, Fajrin, Wibowo}

\subsection{Diagram Alir}

Thermohygrometer dengan Penyimpanan Data untuk Monitoring Kamar Bedah

Gambar 2.2 berikut merupakan gambar diagram alir modul thermohygrometer yang dibuat:

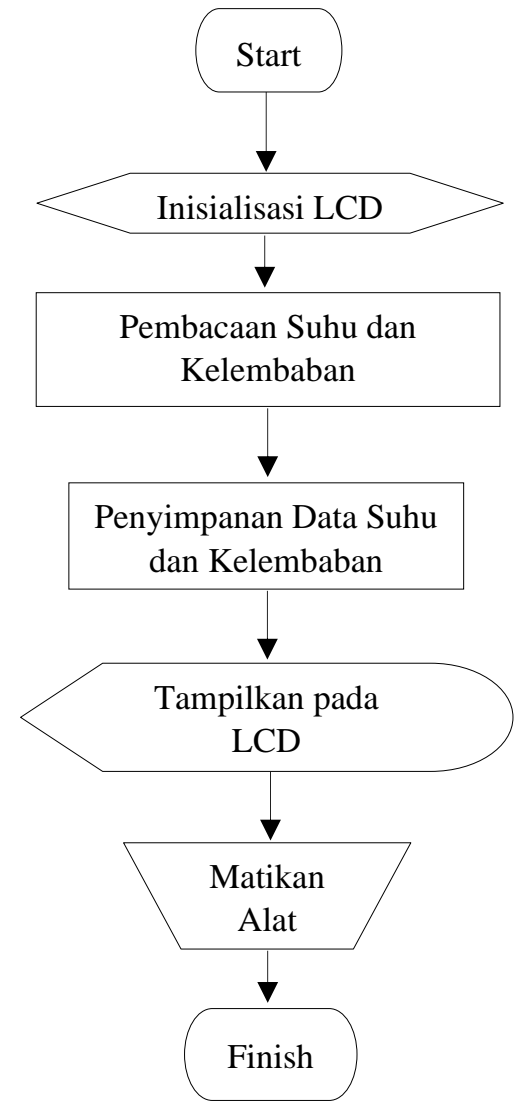

Gambar 2.2 Diagram Alir Alat

Dari Gambar 2.2, dapat dilihat bahwa proses perancangan alat diawali dengan Start kemudian terjadi inisialisasi input-output mikrokontroler dan antarmuka LCD 2 X 16. Kemudian sensor akan membaca suhu dan kelembaban ruangan, dan akan otomatis tersimpan pada SD card. Selanjutnya, data suhu dan kelembaban yang telah terdeteksi oleh sensor akan ditampilkan pada display LCD.

\section{HASIL DAN PEMBAHASAN}

Pengujian alat dilakukan dengan membandingkan antara alat yang dibuat dengan thermohygrometer digital merk HTC-1. Pengambilan data dilakukan dari hari sabtu, minggu, senin dan selasa tanggal 22 s/d 25 Juli 2017. Masing-masing data mewakili suhu rendah, suhu sedang dan suhu tinggi. Untuk suhu rendah diambil diruangan ber AC dengan suhu 22oC, suhu sedang diambil di ruang kamar mandi dengan suhu $260 \mathrm{C}$, dan suhu tinggi dengan suhu ruangan $430 \mathrm{o}$. Data yang tersimpan merupakan data suhu, kelembaban, hari, tanggal, bulan dan tahun.

\subsection{Hasil Pengukuran dan Pengujian}

Pengujian dilakukan dengan membandingkan suhu dan kelembaban menggunakan modul thermohygrometer yang dibuat dengan alat pembanding thermohygrometer HTC-1 LCD Digital Temperature Humidity Meter. yang diambil pada kondisi suhu rendah, sedang, dan tinggi. Data diambil setiap satu menit sekali selama 20 menit. Tabel 3.1 dibawah ini merupakan tabel hasil pengukuran dan pengujian:

Tabel 1. Data Hasil Pengukuran dan Pengujian

Medika Teknika : Jurnal Teknik Elektromedik Indonesia, Vol 02 No. 1, Oktober $2020 \mid 42$ 
Amalia, Fajrin, Wibowo

Thermohygrometer dengan Penyimpanan Data untuk Monitoring Kamar Bedah

\begin{tabular}{|c|c|c|c|c|c|}
\hline \multicolumn{2}{|c|}{ 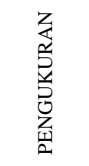 } & $\begin{array}{c}\text { RATA- } \\
\text { RATA } \\
\text { Alat } \\
\text { penelitian }\end{array}$ & $\begin{array}{l}\text { RATA-RATA } \\
\text { PEMBANDING }\end{array}$ & ERROR & $\begin{array}{c}\text { STANDAR } \\
\text { DEVIASI } \\
\text { (SD) }\end{array}$ \\
\hline \multirow{3}{*}{ 疋 } & 1 & $\begin{array}{c}22.829 \\
{ }^{\circ} \mathrm{C}\end{array}$ & $22.07^{\circ} \mathrm{C}$ & $3 \%$ & 0.779 \\
\hline & 2 & $\begin{array}{c}26.4825 \\
{ }^{\circ} \mathrm{C}\end{array}$ & $26.22^{\circ} \mathrm{C}$ & $1 \%$ & 0.423 \\
\hline & 3 & $\begin{array}{c}43.6855 \\
{ }^{\circ} \mathrm{C} \\
\end{array}$ & $44.81^{\circ} \mathrm{C}$ & $1 \%$ & 1.43 \\
\hline \multirow{3}{*}{ 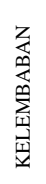 } & 1 & $64.1 \%$ & $63.5 \%$ & $1 \%$ & 0.774 \\
\hline & 2 & $84.92 \%$ & $84.85 \%$ & $0.08 \%$ & 2.458 \\
\hline & 3 & $\begin{array}{c}44.295 \\
\%\end{array}$ & $45.78 \%$ & $2.11 \%$ & 4.697 \\
\hline
\end{tabular}

Pengukuran pertama, diambil diruangan bersuhu rendah (ruang AC), dilakukan pada pagi hari dimulai pada pukul 9:13:51 WIB s/d 9:34:51 WIB, hari Selasa/25/7/17. Dari data pada Tabel 4.1 diketahui rata-rata suhu alat yang dibuat yaitu $23.829^{\circ} \mathrm{C}$, rata-rata suhu alat pembanding yaitu $22.07^{\circ} \mathrm{C}$, rata-rata kelembaban modul yaitu $64.1 \%$, rata-rata kelembaban alat pembanding yaitu $63.5 \%$, standar deviasi pada suhu modul yaitu 0.779 , standar deviasi pada kelembaban modul yaitu 0.774 .

Pengukuran kedua diambil diruangan bersuhu sedang (ruang kamar mandi), dilakukan pada pagi hari dimulai pada pukul 8:40:49 WIB sampai 9:1:49 WIB, hari Senin/24/7/17. Didapatkan hasil rata-rata suhu alat yang dibuat yaitu $26.4825^{\circ} \mathrm{C}$, rata-rata suhu alat pembanding yaitu $26.22^{\circ} \mathrm{C}$, rata-rata kelembaban modul yaitu $84.92 \%$, rata-rata kelembaban alat pembanding yaitu $84.85 \%$, standar deviasi pada suhu modul yaitu 0,423 . Standar deviasi pada kelembaban modul yaitu 2.458 .

Pengukuran ketiga diambil diruangan bersuhu tinggi, dilakukan pada malam hari dimulai pada pukul 21:39:47 WIB sampai 22:01:53 WIB, hari sabtu/22/7/17. Didapatkan hasil rata-rata suhu alat yaitu $43.6855^{\circ} \mathrm{C}$, rata-rata suhu alat pembanding yaitu $44.295^{\circ} \mathrm{C}$, rata-rata kelembaban modul yaitu $44.81 \%$, rata-rata kelembaban alat pembanding yaitu $45.78 \%$, standar deviasi suhu pada modul yaitu 1.43, dan standar deviasi pada kelembaban modul yaitu 4.697.

Data-data tersebut berhasil tersimpan pada $S D$ card, yang membuktikan bahwa proses penyimpanan data berhasil dengan format penyimpanan data suhu, kelembaban, hari, tanggal, bulan dan tahun. Ruangan-ruangan tempat pengambilan data sudah mempresentasikan ruangan kamar bedah, diamana suhu yang dianjurkan di ruangan bedah yaitu $19^{\circ} \mathrm{C}-24^{\circ} \mathrm{C}$ dan kelembaban 45\%-60\% RH dan hasil dari pembacaan suhu tersebut telah membuktikan bahwa sensor yang digunakan dapat membaca suhu dan kelembaban dengan akurat, serta dapat membaca suhu dan kelembaban yang rendah hingga tinggi.

\subsection{Hasil Uji Penyimpanan Data}

Setelah dilakukannya pengujian pengambilan data, alat thermohygrometer telah berhasil membaca suhu dan kelembaban dan berhasil menyimpan data. Data suhu dan kelembaban yang tersimpan, dappat dilihat dengan cara memasukan SD Card ke dalam slot memori SD Card pada laptop / komputer, selanjutnya data tersebut dapat dilihat di komputer dengan format data .txt.

Di dalam $S D$ card tersebut memuat data berupa suhu dan kelembaban pada saat alat dinyalakan hingga alat dimatikan serta penanggalan waktunya, alat thermohygrometer ini disetting dapat menyimpan data setiap satu menit sekali. Adapun gambar dari hasil penyimpanan data suhu dan kelembaban alat thermohygrometer dapat dilihat pada Gambar 3.1 berikut ini : 
Amalia, Fajrin, Wibowo

Thermohygrometer dengan Penyimpanan Data untuk Monitoring Kamar Bedah

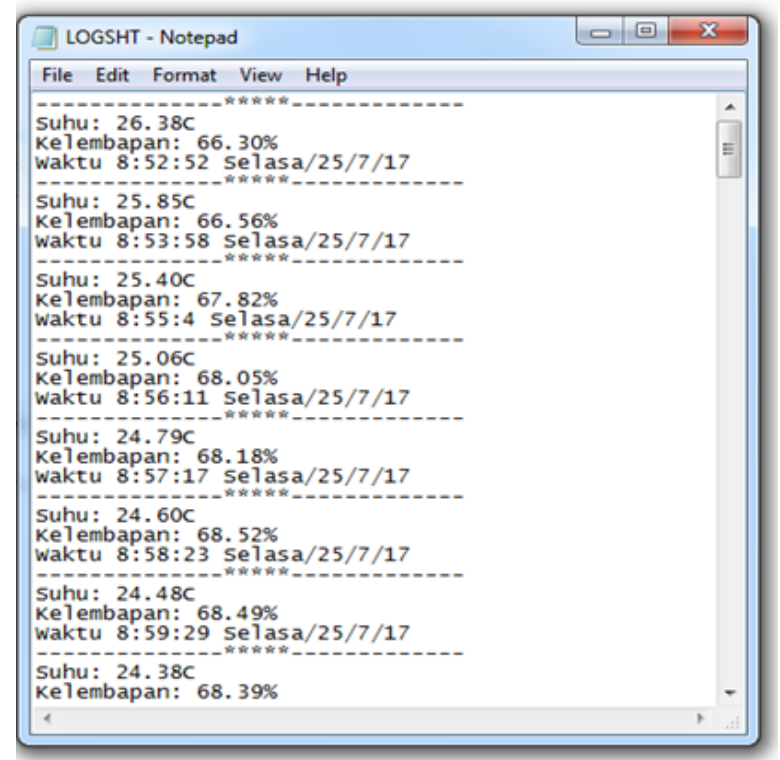

Gambar 3.1 Hasil Penyimpanan Data Suhu dan Kelembaban Thermohygrometer

\section{KESIMPULAN}

Setelah dilakukannya uji coba alat dengan membandingkan thermohygrometer yang dibuat dengan alat thermohygrometer HTC-1 LCD Digital Temperature Humidity Meter, alat dapat bekerja dengan baik sehingga didapatkan hasil standar deviasi tertinggi pada data suhu yaitu $1,43^{\circ} \mathrm{C}$ dan standar deviasi tertinggi pada data kelembaban yaitu 4,697\%. Didapatkan nilai error suhu tertinggi yaitu $3 \%$ dan error kelembaban tertinggi yaitu $2,11 \%$. Alat yang dibuat mempunyai penyimpanan data, dan telah berhasil menyimpanan data dalam bentuk file txt, berupa data suhu, kelembaban, waktu, hari, tanggal, dan tahun. $S D$ card menyimpan data setiap satu menit sekali dan mempunyai kapasitas penyimpanan data hingga 8 GB memory.

\section{DAFTAR PUSTAKA}

[1] M. Box, "Suhu dan Kelembaban Pada Rumah Sakit," http://hvactechnic.blogspot.co.id/2013/10/suhu-kelembaban-pada-rumah-sakit.html, 2013. 12/12/2016.

[2] K. 1204/Menkes/SK/x/2004 T. P. K. L. R. Sakit, Keputusan Menteri Kesehatan Republik Indonesia Nomor: 1204/Menkes/Sk/X/2004 Tentang Persyaratan Kesehatan Lingkungan Rumah Sakit. Indonesia, 2004, pp. 1-50.

[3] Anonim, "Info Kamar Operasi," http://ibsrsudsleman.blogspot.co.id, 2010. 12/12/2016.

[4] E. Warganegara, E. Apriliana, F. Kedokteran, and U. Lampung, "IDENTIFIKASI BAKTERI PENYEBAB INFEKSI LUKA OPERASI ( ILO ) NOSOKOMIAL PADA RUANG RAWAT INAP BEDAH," Jurnal Fak. Kedokt., no. 978, pp. 1-5, 2012.

[5] F. A. Fauzi, "Thermohygrometer-Project," Poltekes Kemenkes Surabaya, 2014.

[6] R. Hidayat, "Mikrokontroller ATMega16," http://rOfqh1.blogspot.co.id/2012/04/microcontroller-atmega-16.html, 2016. 12/12/2016 .

[7] N. Murali, "Tentang DS 1307," http://www.instructables.com/id/Arduino-Real-Time-ClockDS1307/.12/12/2016.

[8] Indoware, "Modul SD card Arduino," https://indo-ware.com/produk-2735-micro-sd-cardmodul-spi-antarmuka-mini-card-reader-tf.html. ., 2016. 12/12/2016 .

[9] Wikipedia, "sd card," https://id.wikipedia.org/wiki/MicroSD, 2016. 12/12/2016.

[10] Ghassan, "SD card," http://info-infoharian.blogspot.co.id/2013/01/mengenal-sd-cardmicro-sd-dan-sdhc.html, 2013. 12/12/2016.

Medika Teknika : Jurnal Teknik Elektromedik Indonesia, Vol 02 No. 1, Oktober $2020 \mid 44$ 